\title{
Development of a technique for assessing veld condition in Etosha National Park, Namibia, using key herbaceous species
}

\author{
W.P. DU PLESSIS, G.J. BREDENKAMP and W.S.W. TROLLOPE
}

Du Plessis, W.P., G.J. Bredenkamp and W.S.W. Trollope. 1998b. Development of a technique for assessing veld condition in Etosha National Park, Namibia, using key herbaceous species. Koedoe 41(1): 19-29. Pretoria. ISSN 0075-6458.

A technique based on the potential of key herbaceous species to produce acceptable herbaceous forage for consumption by herbivores, and fuels for veld burning, was developed in the Etosha National Park, Namibia. Twenty seven key species were selected out of a total of 108 recorded. Forbs and bare ground were treated as two individual "species". The key species selected for each plant community included at least five species, of which at least one Decreaser and one Increaser species had to be present. Multiple regression models, which were developed using these key species, are used to accurately estimate the forage and fuel potential of the veld, and also indicate trends in the condition of the grass sward.

Key words: Decreaser, Etosha National Park, forage potential, fuel potential, Increaser, key herbaceous species.

W. P. du Plessis, Ministry of Environment \& Tourism, Etosha Ecological Institute, P.O. Box 13, Okaukuejo, Via Outjo, Namibia; G.J. Bredenkamp, Department of Botany; University of Pretoria, Pretoria, 0002 South Africa; W.S.W. Trollope, Sub-Department of Pasture Science, Faculty of Agriculture, University of Fort Hare, Alice, South Africa.

\section{Introduction}

This paper is part of a research program to identify key herbaceous species for the effective monitoring of veld condition and ecological status. Veld condition refers to the condition of the vegetation in relation to some functional characteristics, for example maximum forage production potential and resistance to soil erosion (Trollope et al. 1989). Ecological status refers to the abundance of Decreaser or Increaser species in a herbaceous sward. Decreaser species are dominant in veld with a good condition but decrease in dominance with poor veld management and/or with below average rainfall. Increaser species are dominant in veld which is under or over-utilised (Tainton 1981).

Various subjective and objective methods with an ecological and/or an agronomic base have been developed, reviewed and evaluated for veld condition assessment in southern Africa. The assessment of veld condition in
Namibia and in particular in the Etosha National Park (Etosha) received little attention until 1988. The lack of a long-term quantitative data base to detect changes in the vegetation of Etosha, on which management decisions could be based, became apparent. Current botanical research in Etosha is, therefore, aimed at establishing a database of information that is useful, i) for making management decisions based on single sampling periods and, ii) to detect species and environmental trends in future monitoring programs.

In terms of the management requirements of Etosha, the condition of the grass sward is understood as its ability to produce forage for grazing animals, grass fuel to support veld fires, and to resist soil erosion. With regards to the forage and fuel production potential of the veld, Trollope et al. (1989) have shown that the botanical composition of the grass sward accurately reflects the forage and fuel potential because different grass species 


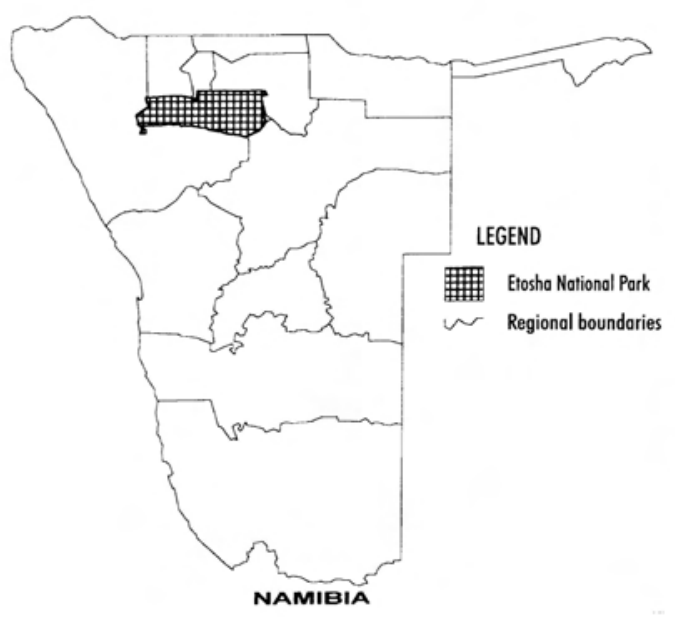

Fig. 1. Location of Etosha National Park in northern Namibia.

differ in their genetic ability to produce herbaceous material that can be used as forage and/or fuel. Trollope (1990) used the concept of forage and fuel factors to describe the potential of the different grass species to produce forage and fuel. A similar procedure was followed in Etosha where forage and fuel factors were subjectively allocated to the different grass species recorded in the park. This was based on field observations and experience. Additionally, forage factors were generated for the different grass species using statistical procedures (Du Plessis 1992).

This paper reports on the procedure used to assess veld condition in Etosha. A technique based on key herbaceous species was developed using stepwise multiple regression modeling.

\section{Study area}

The study was conducted in Etosha with central coordinates at $19^{\circ} \mathrm{S}, 16^{\circ} \mathrm{E}$. The park, with a size of $22915 \mathrm{~km}^{2}$ (Du Plessis 1997) is located in a semi-arid region of northern Namibia (Fig. 1). Three main seasons are recognised, i.e. a wet warm season from January to April, a dry cold season from May to August and a dry warm season from September to December. Rainfall varies from a long-term mean annual rainfall of 445 $\mathrm{mm}$ in the east, to $309 \mathrm{~mm}$ in the west of the park. Rainfall occurs mainly between January and April, with the highest precipitation recorded during February (Le Roux 1980). Temperatures at Okaukuejo, in the center of the park, range from a mean maximum of $34.8^{\circ} \mathrm{C}$ and a mean minimum of $17.7^{\circ} \mathrm{C}$ in November to a mean maximum of $25.0^{\circ} \mathrm{C}$ and a mean minimum of $6.0^{\circ} \mathrm{C}$ in July (Beyers \& Katziambirtas 1987). Frost may occur during the winter months.

Thirty plant communities have been identified in Etosha (Le Roux et al. 1988). During this study, nine of these were surveyed during April to May

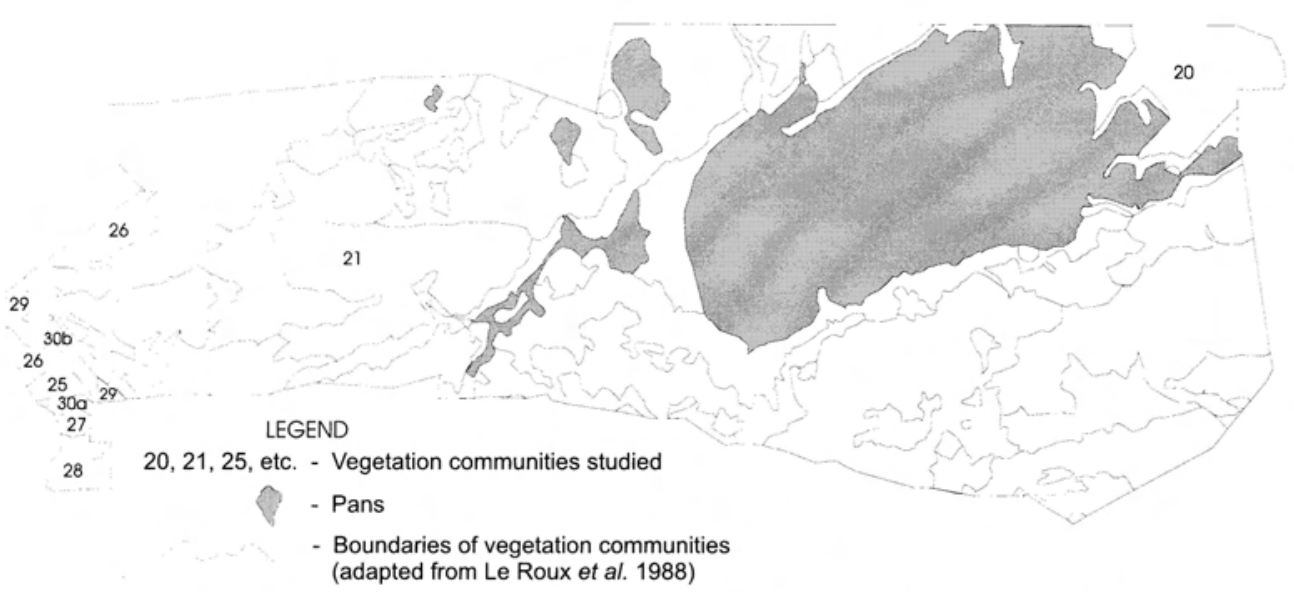

Fig. 2. The location of nine plant communities investigated in Etosha National Park, Namibia. 
in the years 1989 to 1991 (Fig. 2). These plant communities were located in the far west (i.e. communities 25, 26, 27, 28, 29, 30a \& 30b), central west (community 21) and north east (community 20). They were chosen as they constituted the preferred tall grass grazing areas in the park and provided a wide range of veld conditions along a degradation gradient. No data existed previously for these communities to enable the determination of change in herbaceous species frequency. Although ungulates in Etosha are most abundant in the short-grassveld plant community (Le Roux et al. 1988), this community was not included in the current study because data already existed to monitor changes effectively (Nott 1985). The vegetation units are closely associated with soil type, are geologically heterogeneous and include granite, quartzite, shale, sandstone, dolomite and calcrete as part of the Basement complex, Khoabendes Group, Damara Supergroup and Kalahari Beds (Le Roux 1980).

\section{Methods}

\section{Field work}

Sample plots were systematically selected throughout the nine communities. The floristic composition of the herbaceous component was determined in 412 sample plots in the nine communities. Eighty six sample plots were selected in community 20,80 in community 21,65 in community 25,24 in community 26,16 in community 27,72 in community 28 , 35 in community 29,16 in community 30 a and 18 in community $30 \mathrm{~b}$. The percentage frequency of species was determined by identifying the closest species to a thin metal rod placed approximately every two meters apart. This is an adaptation to the wheel \& step-point methods which were evaluated by Mentis (1981). At each $100 \mathrm{~m}$ x $50 \mathrm{~m}$ sample plot area, one hundred points placed in two parallel transects $25 \mathrm{~m}$ apart, were assessed. The number of points and sample plot dimensions were based on results of Trollope (1990) and Hardy \& Walker (1991). The nearest herbaceous species or dwarf shrub to a point within a $400 \mathrm{~mm}$ radius was recorded. A radius of $400 \mathrm{~mm}$ was used as experience has shown that this represents the average maximum distance between rooted herbaceous plants in situations where the veld is in a non-degraded condition. This data set (DATA A) included, therefore, annual and perennial species. Non-grass herbaceous species were combined as forbs.

At each point, the nearest perennial herbaceous plant species (grasses or forbs) was also recorded. The recording of this data set (DATA P) was considered to be important because of the insensitivity of the nearest plant method to detect real changes in the sometimes less abundant, but more significant perennial species component (Stuart-Hill 1988; Snyman et al. 1990). The frequency of occurrence of the nearest herbaceous species or dwarf shrub (DATA A) and of the nearest perennial herbaceous species or dwarf shrub (DATA P) was therefore obtained at each sample plot. If no herbaceous species occurred within $400 \mathrm{~mm}$ radius of the point, it was recorded as bare ground. This gave an indication of plant density (Mentis 1984), which is also an important additional parameter for recording real changes in veld condition (Danckwerts \& Teague 1989).

Standing crop was subjectively estimated for each sample plot. These estimations have been refined by calibrating a disc pasture meter in Etosha to assess the standing crop, and hence the fuel load, as part of the burning strategy in Etosha (Du Plessis 1997). Basal cover classes have been defined by subjectively estimating the basal cover of selective areas with no herbaceous basal cover to areas with clearly very high basal cover. Annual and perennial species' basal cover have been subjectively separated in the surveys (Du Plessis 1992). Experience has shown that different observers may often interpret the basal cover and standing crop differently by one class, but very seldom by two classes. This subjective estimation process, therefore, was considered valuable in indicating relatively large and important (or drastic) changes or differences in basal cover or standing crop accurately, but was not considered accurate for indicating relatively small changes.

Sample plots were subjectively located in homogeneous vegetation units within each plant community and represented various visually distinguishable degrees of degradation. For this purpose gradients were selected from watering points and other areas of high animal concentration to relatively ungrazed veld.

High grazing intensities and drought are perceived to have the same long-term detrimental effect on species composition and abundance. In this study, the effect of grazing intensity or rainfall amount on environmental degradation was not clearly distinguishable. Therefore, the term "degradation gradient", incorporating grazing and rainfall effects, was more appropriate to use than the term "grazing gradient".

\section{Data analysis}

Species were first subjectively grouped into ecological categories (Decreasers \& Increasers), and then 
objectively grouped into ecological categories according to their change in frequency along a degradation gradient, using the DECORANA ordination technique and subsequent polynomial regression. Final ecological categories assigned to each species were based on a combination of objective and subjective categorisation (Du Plessis 1992; Du Plessis et al. 1998a).

The following Decreaser and Increaser categories were distinguished (Trollope 1990).

Category 1: Species dominant in under-utilised veld (Increaser I species).

Category 2: Species abundant in lightly-grazed veld, decreasing with under or over-utilisation (Decreasers).

Category 3: Species with low abundance in under-utilised or lightly-grazed veld which tend to increase in abundance when vegetation is moderately grazed (Increaser 2 a species).

Category 4: Species which are more abundant in moderately over-utilised veld (Increaser 2b species).

Category 5: Species becoming dominant in severely over-utilised veld (Increaser $2 \mathrm{c}$ species).

Forage and fuel factors were then estimated for each species on a scale of 0 to 10 . This was done subjectively (incorporating the genetic production potential and acceptability to grazers in terms of leafiness, steaminess and volatile substances) and in comparison with three relatively objective statistical techniques (Du Plessis 1992). In the first technique, species eigenvalues on the DECORANA X-axis, representing the degradation gradient (Du Plessis et al. 1998a), were transformed so that the highest value was equivalent to zero, and the lowest value equivalent to ten. This was done in accordance with the method of Hurt \& Hardy (1989), since it was found (Du Plessis et al. 1998a) that the Increaser 1 and Decreaser species were most often situated to the left of the ordination (with corresponding low eigenvalues), and Increaser 2 species were mostly situated to the right (with higher eigenvalues). Where the gradient along the axis was reversed, the transformation of species eigenvalues was also reversed.

Secondly, the DECORANA X-axis of each community was divided into 10 units of equal length, and each unit designated a value from $0-10$. The highest value (low eigenvalue) was most often situated to the left of the ordination, and the lowest value (high eigenvalue) was situated to the right (except where indicated differently) (Du Plessis 1992). This was done with the perception that Decreasers produce more acceptable forage than Increasers. The highest frequency of each species along the degradation gradient, determined by polynomial regression (Du Plessis 1992; Du Plessis et al. 1998a), was correlated with the designated value $(0-10)$ on the gradient.

Thirdly, the individual ecological categories (Decreaser, Increaser 1, Increaser $2 \mathrm{a}-\mathrm{c}$ ) were subjectively assigned a value between 0-10 (Du Plessis 1992). Individual species therefore received the same value as the ecological group in which they were initially grouped.

The results from these three methods were compared with the subjectively chosen forage factors using linear regression analysis (Du Plessis 1992). A final list of forage factors for all species was compiled using a combination of the results of these methods. Subjectively chosen fuel factors were not compared with statistically derived results, since Trollope (1990) found a significant correlation between forage and fuel factors in the Kruger National Park.

The forage and fuel factors represent the perceived sustainable forage and fuel production potential of the different herbaceous species, i.e. their genetic potential to produce acceptable forage for grazers and fuel for burning (Trollope 1990). The forage factor was designed to represent the potential of a plant species to produce acceptable forage in terms of the most abundant grazers present in Etosha. These are springbok Antidorcas marsupialis (Zimmermann, 1970), blue wildebeest Connochaetes taurinus (Burchell, 1823), gemsbok Oryx gazella (Linnaeus, 1758) and burchell's zebra Equus burchellii (Gray, 1824).

Forage and fuel scores were calculated for all of the vegetation sample plots assessed. These scores were calculated by multiplying the frequency of each species in each sample plot with its respective forage and fuel factor, and then totaling the scores for each survey (Du Plessis 1992). These scores were grouped into five classes ranging from a very low forage/fuel potential to an excellent potential. Very low scores were classed from 0 to 110 , low scores from 111 to 220 , moderate scores from 221 to 330 , high scores from 331 to 440 , very high scores from 441 to 550 , and extremely high scores higher than 550. These classes were subjectively defined so that very high scores represent the typical in situ situation for lowly utilised Decreaser veld in prime condition in Etosha. Small patches of the veld may have extremely high scores (above 550), but this never occurs over an entire plant community. Therefore, the scoring system is based around the common occurring values from 0 to 550 . 
Forage and fuel scores were calculated for the nearest species (DATA A) and for the nearest perennial species (DATA P). The relationship between DATA $A$ and $P$ was statistically assessed using the Kolmogorov Smirnov Two-sample test (Du Plessis 1992). When the veld is in a highly-utilised condition (highly degraded condition), forage scores determined from the nearest species data (DATA A) are higher than forage scores from the nearest perennial data (DATA P). When veld is less utilised and has a higher score, forage scores from DATA P are higher than forage scores from DATA A. The same relationship as above was found between fuel scores from DATA A and DATA P. The results further indicate that in veld with a very high forage and fuel potential, it would not be necessary to record the nearest perennial species (DATA P), but only the nearest species (DATA A), because perennial species normally dominate veld with a very high potential in Etosha.

Key-herbaceous species were identified separately for each of the nine plant communities, using stepwise multiple regression analysis. Data for communities $25 \mathrm{~A}, 25 \mathrm{P}, 26 \mathrm{P}, 29 \mathrm{P}, 30 \mathrm{aP}$ and $30 \mathrm{bP}$ had a relatively high abundance of perennial forbs and dwarf shrubs and these species were included in the analysis. Community 27 could not be analysed in this way because the sample size was too small $(n=16)$. The related communities 26 and 29 were assessed together, as well as communities $30 \mathrm{a}$ and $30 \mathrm{~b}$. The reason for this was also a small sample size which did not allow the use of stepwise regression analysis on each of these communities separately. Community 27 was not grouped with any of the other communities due to its different species composition. Data $\mathrm{A}$ and $\mathrm{P}$ were analysed separately for all communities. Two sets of forage key species, and two sets of fuel key species for each community were, therefore, identified.

The percentage frequencies of the different grass species were designated as independent variables, and the forage score as the dependent variable. Trollope (1990) used the same key grass species derived from the forage scores to develop a fuel model for predicting fuel scores. This was done in order to restrict the number of key species. During the present study, the fuel score was used additional$l y$ as the dependent variable to identify separate fuel key species for each of the plant communities investigated.

The selection of key grass species was designed to include at least five species for each plant community. At least one Decreaser and one Increaser species were present in the selection. Once the key species had been identified for each vegetation type, an overall model was developed for Etosha where all the forage data (DATA A and DATA P being analysed separately) were combined and a multiple regression analysis conducted using the key grass species' percentage frequencies as the independent variable, and the forage scores as the dependent variable. The rationale behind this was to ensure that the chosen key species were represented in all the vegetation variations assessed during the present study. A simplified forage model could then be used throughout the park.

The individual key species models developed for each of the communities assessed, were statistically tested using independent data from each community separately. Independent species frequency data were obtained by conducting additional surveys in each of the plant communities. These surveys were similar to the main surveys described in this paper.

\section{Results and discussion}

\section{Key species selected}

The species that were selected as key forage and key fuel species in the different plant communities, together with the calculated forage and fuel scores, are presented in Tables 1 and 2, respectively. Forage key species are not necessarily the same as the fuel key species for the same plant community. The species selected using the forage and fuel models are given for DATA A and P separately. Tables 1 and 2 indicate that the perennial data (DATA P) produced higher key forage and fuel equations respectively (higher coefficient of determination) than the nearest species frequency data (DATA A). The perennial species component is a better indicator of the ecological position of a sample plot compared to the nearest species component (mostly annual species), because significant changes in abundance between Decreaser and Increaser perennial species are most likely to take place only after significant changes occurred in the degradation status of an area. Annual species are responding more rapidly in abundance to 


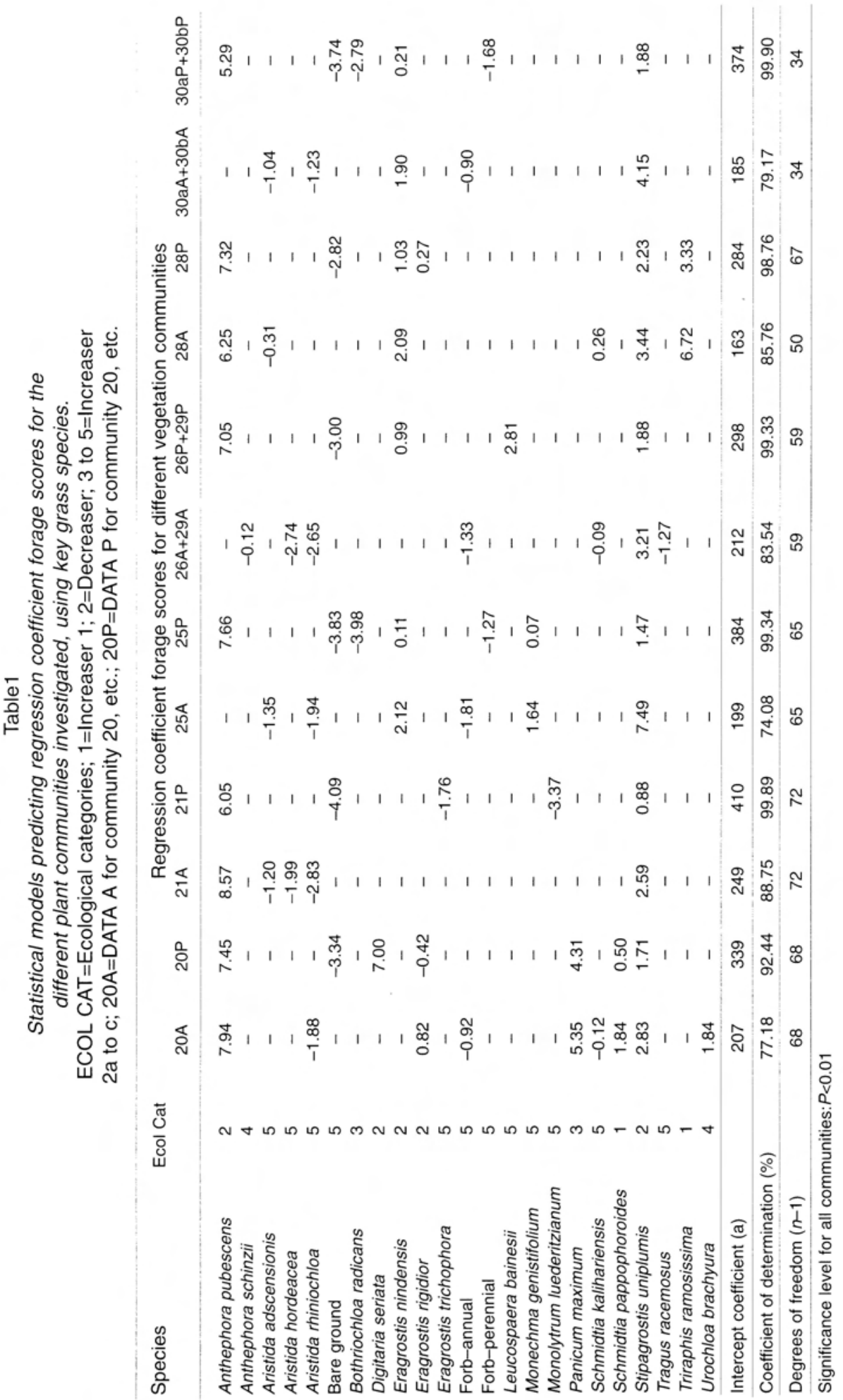




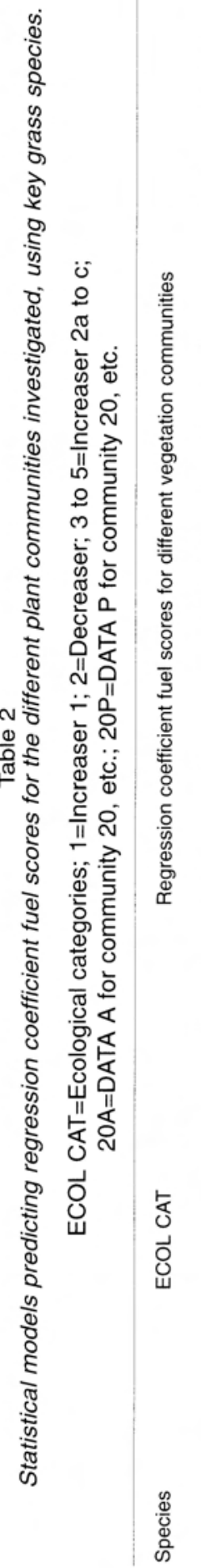

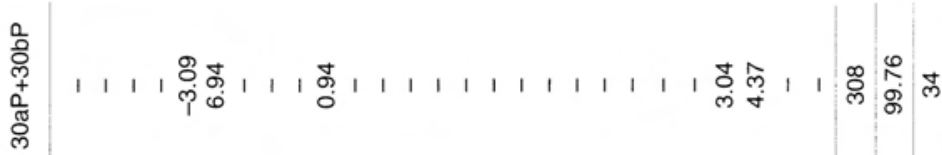

兽

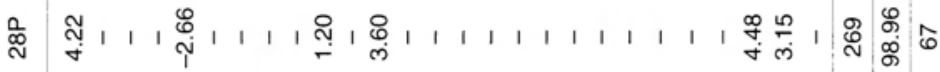

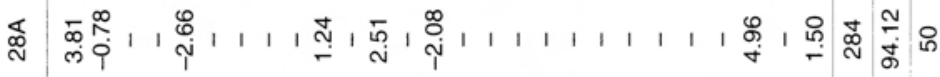

离

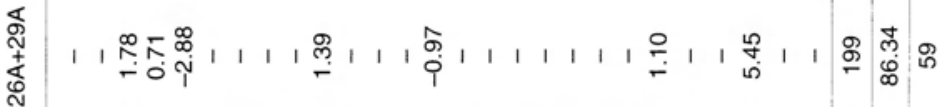

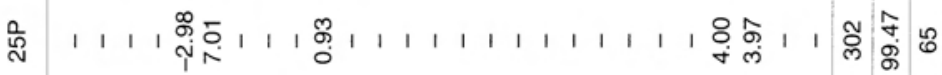

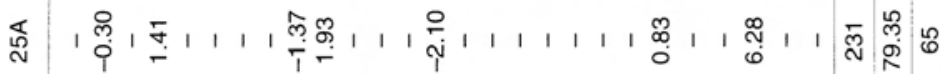

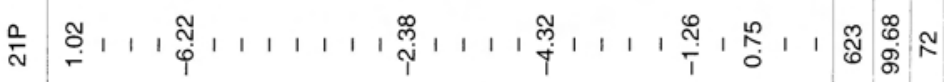

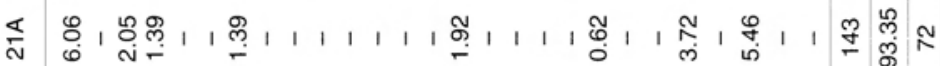

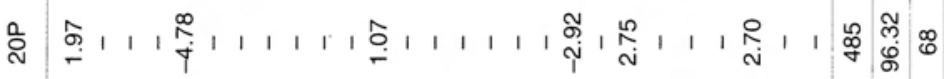

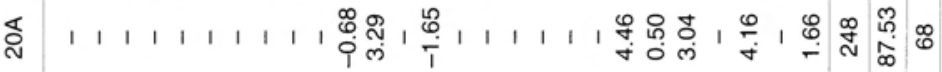

ป

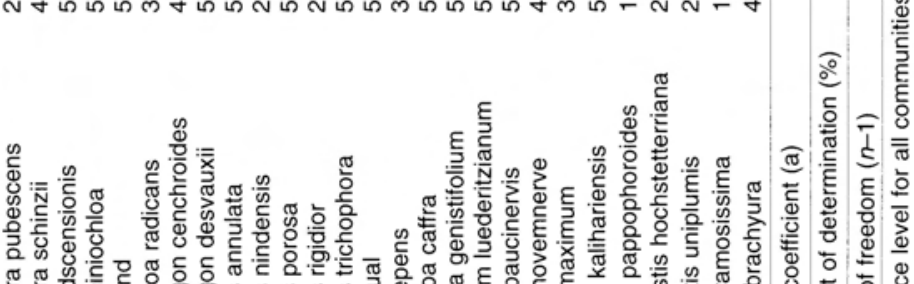

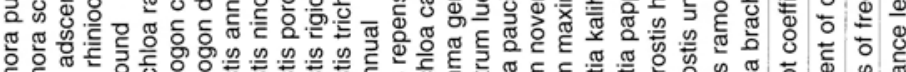

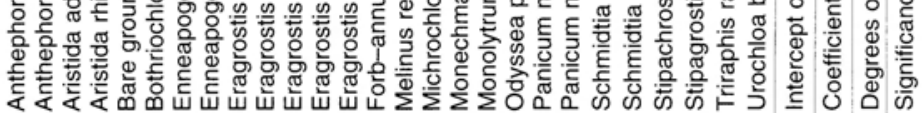


Table 3

Statistical models predicting regression coefficient forage scores of all plant community frequency data (DATA A) combined, using key grass species $(\mathrm{df}(\mathrm{n}-1)=270 ; \mathrm{P}<0.05)$

ECOL CAT $=$ Ecological categories; $1=$ Increaser 1 ; $2=$ Decreaser; 3 to $5=$ Increaser 2 a to $c$; $d f=$ Degrees of freedom: $P=$ Significance level

Species
Anthephora pubescens
Anthephora schinzii
Aristida hordeacea
Aristida rhiniochloa
Eragrostis nindensis
Eragrostis rigidior
Forb-annual
Panicum maximum
Schmidtia kalihariensis
Schmidtia pappophoroides
Stipagrostis uniplumis
Urochloa brachyura
Intercept coefficient (a)
Coefficient of
determination (\%)

ECOL Regression

CAT coefficient forage scores

2

$-0.19$

$5-2.12$

$5-1.39$

$2 \quad 1.26$

2
5 0.89

$5-0.98$

$3 \quad 5.98$

$5-0.33$

$1 \quad 1.68$

$2 \quad 3.6$

$4 \quad 1.78$

206

69.85 small changes in rainfall and grazing pressure than perennial species. Small changes in abundance of annual species, therefore, do not represent significant changes in ecological status or significant changes in degradation. However, small changes in annual species abundance have important implications on forage or fuel availability. The nearest individual species data will, therefore, be used to assess the current potential of the veld to provide forage or fuel, and the perennial species data will be used to determine the ecological status of a community,

Table 3 provides a list of the forage key species selected and forage scores calculated using all of the key species frequency data of the different plant communities that were investigated. The forage scores used in the multiple regression as the dependent variables, were calculated by multiplying

Table 4

Key species forage score assessment sheet using community 21A as an example. Space is provided for interpreting the forage score and subjectively estimating the basal cover and standing crop

Ecological

Category

Decreaser

Increaser 2

Constant (a)

Other species

Total \% frequency

\begin{tabular}{ccc} 
& \multicolumn{2}{c}{ Forage score } \\
\cline { 2 - 3 } \% Frequency & Factor & Score \\
\hline 10 & 8.57 & 85.7 \\
30 & 2.59 & 77.7 \\
22 & -1.2 & -26.4 \\
5 & -1.99 & -9.95 \\
33 & -2.83 & -93.4 \\
\end{tabular}

249

Forage score

282.65

\begin{tabular}{|c|c|c|c|c|c|c|c|}
\hline \multicolumn{2}{|c|}{ Interpretation of forage score } & \multicolumn{3}{|c|}{ Interpretation of basal cover } & \multicolumn{3}{|c|}{ Interpretation of standing crop } \\
\hline Forage potential & Tick & \multirow[b]{2}{*}{$\begin{array}{l}\text { Potential ' } \\
\text { (and \% cover) }\end{array}$} & \multicolumn{2}{|c|}{ Tick } & \multicolumn{3}{|c|}{ Tick } \\
\hline \multirow{2}{*}{$\begin{array}{l}\text { Very low }(0-110) \\
\text { Low }(111-220) \\
\text { Moderate }(221-330) \\
\text { High }(331-440) \\
\text { Very high }(441-550) \\
\text { Extremely high }(>550)\end{array}$} & \multirow{2}{*}{$\mathrm{X}$} & & Annual & Perennial & $\begin{array}{l}\text { Potential' } \\
\text { (and standing crop in } \mathrm{kg} / \mathrm{ha} \text { ) }\end{array}$ & Annual & Perennial \\
\hline & & \multirow[t]{2}{*}{$\begin{array}{l}\text { Very low }(0-0.05) \\
\text { Low }(0.06-2.0) \\
\text { Moderate }(2.1-10) \\
\text { High }(10.1-20) \\
\text { Very high }(>20)\end{array}$} & \multirow[t]{2}{*}{$\mathrm{X}$} & \multirow[t]{2}{*}{$\mathrm{X}$} & $\begin{array}{l}\text { Very low }(0-628) \\
\text { Low }(629-1235) \\
\text { Moderate }(1236-2032) \\
\text { High }(2033-3020) \\
\text { Very high }(3021-4197)\end{array}$ & $\mathrm{X}$ & \multirow[t]{2}{*}{$\mathrm{X}$} \\
\hline See text fo & & & & & Extremely high $(>4197)$ & & \\
\hline
\end{tabular}


the frequency of each species in each sample with its original forage factor and then totaling the scores for each survey. Even though the coefficient of determination $\left(R^{2}\right.$-value) obtained here is relatively high for data of this kind, it is lower than $\mathrm{R}^{2}$-values obtained from the individual communities' key forage species (Table 1). This confirms the expectation that key species selected from nine of the plant communities individually, will be more representative of the individual variation in forage and fuel score than given by a combination of data. It was, therefore, not considered appropriate to apply an overall key species list to estimate forage scores over all plant communities. However, such a combined key species list for accurately assessing the forage and fuel score separately in any plant community of Etosha would be highly advantageous and may be developed as a future research activity.

Table 4 provides an example of a key forage species scoresheet using data from community $21 \mathrm{~A}$. This is based on data from Table 1 . Such a scoresheet should be used at each sample plot during future assessments. It allows forage scores to be interpreted in terms of forage potential, and allows for making a subjective interpretation of the standing crop and basal cover of annual and perennial herbaceous species separately, according to recommendations by Trollope (1986). Such scoresheets will be used for subsequent monitoring of veld condition and ecological status (Decreaser or Increaser abundance) in each community separately. Species that are not key species, but have a high abundance and are encountered during monitoring, should be noted to be able to accurately assess the ecological status in that site. This is especially important if such species are Decreaser or Increaser 1 species (Willis \& Trollope 1987).
Table 5

Testing of key forage species developed with independent forage data for each of the communities investigated.

$R=$ Correlation coefficient; $R^{2}=$ Coefficient of determination; $d f=$ Degrees of freedom; $P=$ Significance level $(P<0.01)$

\begin{tabular}{lccc}
$\begin{array}{l}\text { Vegetation } \\
\text { community }\end{array}$ & $R$ & $R^{2}$ & $d f(n-1)$ \\
\hline $20 \mathrm{~A}$ & 0.9338 & 0.8721 & 16 \\
$20 \mathrm{P}$ & 0.9968 & 0.9937 & 16 \\
$21 \mathrm{~A}$ & 0.8786 & 0.7721 & 12 \\
$21 \mathrm{P}$ & 0.9999 & 0.9999 & 12 \\
$25 \mathrm{~A}$ & 0.7219 & 0.5212 & 13 \\
$25 \mathrm{P}$ & 0.9947 & 0.9896 & 16 \\
$28 \mathrm{~A}$ & 0.8462 & 0.7162 & 9 \\
$28 \mathrm{P}$ & 0.9942 & 0.9885 & 15 \\
$26 \mathrm{~A}+29 \mathrm{~A}$ & 0.7965 & 0.6345 & 13 \\
$26 \mathrm{P}+29 \mathrm{P}$ & 0.9907 & 0.9816 & 13 \\
$30 \mathrm{aA}+30 \mathrm{bA}$ & 0.9104 & 0.8290 & 8 \\
$30 \mathrm{aP}+30 \mathrm{bP}$ & 0.9964 & 0.9930 & 8 \\
\hline
\end{tabular}

Testing the key species selected with independent data

Key species and their forage factors, selected for each of the communities separately (Table 1), were tested for their representativeness of forage scores obtained, using independent data from each of these communities (Table 5). The forage scores were calculated by multiplying the frequency of each key species in each independent sample plot with the forage factor developed using the regression equation (Table 1), and then totaling the scores for each survey. These forage scores were then compared to the original forage scores of each plant community separately using linear regression analysis. The analysis were limited to using only the forage score as the dependent variable. It was considered unnecessary to repeat these analyses using the fuel score as the dependent variable, as there was a positive linear correlation between the forage score and fuel score $\left(R^{2}=0.4761 ; d f=389\right)$. Even though some of the communities were analysed using only a relatively small number of independent data, high coefficient of determination values were obtained (Table 5), especially for DATA P. 


\section{Conclusion}

It can be concluded that the key species selected are effective and provide accurate results for monitoring the forage and fuel production potential and ecological status of the veld. The key species method is well suited and of practical use for wildlife managers. Only twenty seven species out of a total of 108 encountered in the communities assessed, need to be identified. These key species are therefore part of four scoresheets. One is used to determine the forage score of the nearest individual key species (DATA A), and another to determine the forage score for the nearest perennial key species (DATA P). The other two scoresheets are used to determine the fuel score for DATA A and P separately.

It can be expected that the key species selected may not be valid to be used further if a plant community enters into a higher or lower "domain of attraction" (Bosch 1989). This is not expected to happen in any of the examined communities in the short-term, but such changes have been observed locally in parts of some communities in Etosha, for example the drastic increase in dwarf shrubs and Acacia nebrownii (Burtt Davy, 1921) shrubs on certain highly utilised areas of the open short-grass plains, and in slight depressions along roads.

This study aimed at providing a pragmatic, reasonably objective method for making management decisions within the context of a complex system. The models described in this study reflect current understanding of how the system operates.

\section{Acknowledgements}

The ministry of Environment and Tourism of Namibia is thanked for supporting this research at the Etosha National Park.

\section{References}

BEYERS, J.J. \& E.E. KatSiambirTAS. 1987. Climate of South West Africa/Namibia. Windhoek: SWA/Namibia Meteorological Survey, Department of Transport. (Series no. 1).

BosCH, O.J.H. 1989. Degradation of semi-arid grasslands of southern Africa. Journal of Arid Environment 16: 165-175.

DANKWERTS, J.E. \& W.R. TEAgue. 1989. Veld management in the eastern Cape. Pretoria: Pasture Research Section, Dept. of Agriculture and Water Supply, Eastern Cape Region.

DU PLESSIS, W.P. 1992. Chapter 4: Formulation of forage and fuel factors for herbaceous plant species in the Etosha National Park. Pp. 82-115. In: DU PLESSIS, W.P. 1992. Development of techniques for the assessment of veld condition in the Etosha National Park, Namibia. M.Sc thesis, University of Pretoria, Pretoria.

DU PLESSIS, W.P. 1997. Refinements to the burning strategy in the Etosha National Park, Namibia. Koedoe 40(1): 63-76.

Du Plessis, W.P., G.J. BRedenkamp \& W.S.W. TROLLOPE. 1998a. Response of herbaceous species to a degradation gradient in the western region of Etosha National Park, Namibia. Koedoe 41(1): 00-00.

HARDY, M.B. \& R.S. WALKER. 1991. Determining sample size for assessing species composition in grassland. Journal of the Grassland Society of South Africa 8(2): 70-73.

HURT, C.R. \& M.B. HARDY. 1989. A weighted key species method for monitoring changes in species composition of Highland Sourveld. Journal of the Grassland Society of South Africa 6(3): 109-113.

LE RouX, C.J.G. 1980. Vegetation classification and related studies in the Etosha National Park. D.Sc. Agricultural thesis, Univ. of Pretoria, Pretoria.

LE Roux, C.J.G., J.O. GRUNOW, J.W. MORRIS, G.J. BREDENKAMP \& J.C. SCHEEPERS. 1988. A classification of the vegetation of the Etosha National Park. South African Journal of Botany 54(1): $1-10$.

MENTIS, M.T. 1981. Evaluation of the wheel-point and step-point methods of veld condition assessment. Proceedings of the Grassland Society of South Africa 16: 89-94.

MENTIS, M.T. 1984. Monitoring in South African grasslands. Pretoria: Council for Scientific and Industrial Research, National Scientific Programmes Unit (South African National Science Programs report no. 91). 
NoTT, T.B. 1985. Vegetation monitoring to determine the extent of goal attainment in Etosha National Park. Department of Agriculture and Nature Conservation in Namibia. (Internal Progress report no. 2).

SNYMAN, D.D., D. GROSSMAN \& N.F.G. RETHMAN. 1990. Tekortkomings van die naasteplantmetode en Dyksterhuis-verwante klassifikasiesisteme om veldtoestande in semi-ariede gebied te bepaal. Journal of the Grassland Society of South Africa 7(4): 273-276.

STUART-HiLL, G.C. 1988. Be careful when using the nearest plant grass survey method in arid areas. Dohne Agriculture 10: 18-23.

TAINTON, N.M. 1981. Veld and pasture management in South Africa. Pietermaritzburg: University of Natal Press.
TrOLlOPE, W.S.W. 1986. Land use surveys: assessment of veld condition in Ciskei. Alice: University of Fort Hare.

Trollope, W.S.W., A.L.F. Potgieter \& N. ZAMBATIS. 1989. Assessing veld condition in the Kruger National Park using key-grass species. Koedoe 32(1): 67-93.

TROLlOPE, W.S.W. 1990. Development of a technique for assessing veld condition in the Kruger National Park using key grass species. Journal of the Grassland Society of South Africa 7: 46-51.

WILlis, M.J. \& W.S.W. TROLlOPE. 1987. Use of key grass species for assessing veld condition in the eastern Cape. Journal of the Grassland Society of South Africa 4: 113-116. 